\title{
Partial nephrogenic diabetes insipidus associated with Castleman's disease
}

\author{
Minah Kim, Hong Sang Choi, Eun Hui Bae, Seong Kwon Ma, Soo Wan Kim and Chang Seong Kim *iD
}

\begin{abstract}
Background: Nephrogenic diabetes insipidus (DI) secondary to a urinary tract obstruction is a rare condition. Herein, we report a case of partial nephrogenic DI due to obstructive uropathy in a patient with Castleman's disease.

Case presentation: A 78-year-old man underwent computed tomography (CT) at his local hospital because of persistent edema of the leg and polyuria (both lasting approximately 2 months); retroperitoneal fibrosis was detected on the CT scan. An abdominal CT scan showed bilateral hydronephrosis, and a surgical biopsy of the para-aortic lymph node revealed Castleman's disease. To resolve the hydronephrosis, a double J stent was inserted; however, his polyuria continued. As his serum osmolality $(311 \mathrm{mOsm} / \mathrm{kg})$ was greater than $300 \mathrm{mOsm} / \mathrm{kg}$, and his serum sodium level was $149 \mathrm{mEq} / \mathrm{L}$, a water deprivation test was not performed. On a vasopressin challenge test, his urine was not sufficiently concentrated to the expected range, indicating partial nephrogenic DI. He was treated with hydrochlorothiazide ( $25 \mathrm{mg} /$ day), and his urine output gradually decreased to within the normal range. The patient recovered uneventfully and underwent treatment for Castleman's disease.
\end{abstract}

Conclusion: To the best of our knowledge, this is the first case of partial nephrogenic DI due to obstructive uropathy associated with Castleman's disease.

Keywords: Castleman's disease, Obstructive uropathy, Nephrogenic diabetes insipidus

\section{Background}

Diabetes insipidus (DI) is a syndrome characterized by the chronic excretion of abnormally large volumes of dilute urine. There are four types of DI: central (pituitary) DI, primary polydipsia, gestational DI, and nephrogenic DI. In central DI, the antidiuretic hormone (ADH) level is lower than normal. Diseases of the hypothalamus-pituitary gland axis may cause central DI. Primary polydipsia is due to the suppression of arginine vasopressin (AVP) secretion by excessive fluid intake, and gestational DI is caused by a deficiency of plasma AVP, resulting from increased hormone degradation by an enzyme made in the placenta [1]. In contrast, nephrogenic DI results from a failure of the kidneys to concentrate the urine due to an insensitivity of the distal nephron to the antidiuretic hormone, AVP.

Nephrogenic DI can be classified as congenital or acquired [2]. Acquired nephrogenic DI has been described

\footnotetext{
* Correspondence: laminion@hanmail.net

Department of Internal Medicine, Chonnam National University Medical School, 42 Jebongro, Gwangju 61469, Republic of Korea
}

in a number of clinical settings; however, nephrogenic DI secondary to a urinary tract obstruction is a rare clinical problem. This condition was first reported in 1954 by Roussak and Oleesky [3]. Ureteral obstruction may result from stones, a transitional cell carcinoma, or external compression (by tumors, enlarged lymph nodes, or retroperitoneal fibrosis).

In 1956, Castleman et al. described an entity involving localized mediastinal lymph node hyperplasia, resembling a thymoma [4]. Castleman's disease, which is diagnosed as retroperitoneal fibrosis with hydronephrosis, has rarely been reported. Herein, we report the first known case of partial nephrogenic DI with hydronephrosis in a patient with Castleman's disease.

\section{Case presentation}

A 78-year-old man was admitted to a local hospital because of leg swelling and polyuria (both lasting for approximately 2 months). He had not received any medication for his complaint. He had no known medical history of hypertension, diabetes mellitus. Physical

(c) The Author(s). 2019 Open Access This article is distributed under the terms of the Creative Commons Attribution 4.0 International License (http://creativecommons.org/licenses/by/4.0/), which permits unrestricted use, distribution, and 
examination showed the patient to be well nourished but he craved for water. Retroperitoneal fibrosis was detected on computed tomography (CT). The retroperitoneal fibrotic tissue was compressing both distal ureters, and bilateral hydronephrosis was identified on CT (Fig. 1a and b). To resolve the hydronephrosis, a double J stent was inserted in the right-side ureter; however, insertion into the left-side ureter failed due to atrophy. To evaluate the cause of the retroperitoneal fibrosis, we decided to perform a laparoscopic surgical biopsy. Because the retroperitoneal fibrotic tissues were too stiff for biopsy, we biopsied the para-aortic lymph node, just adjacent to the fibrotic tissue. The biopsy test results showed the classical characteristics of Castleman's disease (hyaline-vascular type, negative for human herpesvirus 8).

Before the initiation of radiation treatment, he still complained of frequent urination (20 times/day), excessive thirst (visual analogue scale 8) [5], and his urine output was approximately $5 \sim 6 \mathrm{~L} /$ day. His baseline biochemical levels were as follows: blood urea nitrogen, $19.6 \mathrm{mg} / \mathrm{dL}$; creatinine, $1.4 \mathrm{mg} / \mathrm{dL}$; sodium, $149 \mathrm{mEq} / \mathrm{L}$; potassium, 4.8 $\mathrm{mEq} / \mathrm{L}$; chloride, $118 \mathrm{mEq} / \mathrm{L}$; serum osmole, $311 \mathrm{mOsm} /$ $\mathrm{kg}$; and random glucose, $131 \mathrm{mg} / \mathrm{dL}$. On urine analysis, the specific gravity was under 1.005 , representing diluted urine, and the urine osmolality was $148 \mathrm{mOsm} / \mathrm{kg}$. No protein, glucose, or red blood cells were seen on a urine analysis. A basal plasma AVP level was $5.24 \mathrm{pg} / \mathrm{ml}$, which was above the normal range $(0 \sim 4.7 \mathrm{pg} / \mathrm{ml})$. An antinuclear antibody test was performed to further evaluate the retroperitoneal fibrosis. The antinuclear antibody test was positive, with a homogeneous pattern, but the specific tests for extractable nuclear antigen antibodies and double-strand deoxyribonucleic acid were negative.

A water deprivation test was not performed, as his serum osmolality $(311 \mathrm{mOsm} / \mathrm{kg})$, and serum sodium $(149 \mathrm{mEq} / \mathrm{L})$ were above the threshold for maximal AVP secretion (serum osmolality, $300 \mathrm{mOsm} / \mathrm{kg}$; serum sodium, $145 \mathrm{mEq} / \mathrm{L}$ ). Thus, we performed a vasopressin challenge test (Additional file 1: Figure S1). After the vasopressin injection, his urine osmolality increased to $206 \mathrm{mOsm} / \mathrm{kg}$, which was approximately 39\% greater than that at baseline (before the vasopressin injection: $148 \mathrm{mOsm} / \mathrm{kg}$ ). Thus, the urine was not sufficiently concentrated to the expected range, indicating partial nephrogenic DI. Partial nephrogenic DI can be diagnosed as a small elevation (up to 45\%) in urine osmolality after a vasopressin injection, with the urine osmolality remaining well below isosmotic urine. Compared to that in patients with partial nephrogenic DI, patients with partial central DI usually achieve a urine osmolality of $300 \mathrm{mOsm} / \mathrm{kg}$ or higher after a vasopressin injection [6, 7]. After the vasopressin challenge test, he still complained with remained thirst (visual analogue scale 4). We treated the patient with hydrochlorothiazide (25 mg/day), and his urine output gradually decreased to within the normal range (Fig. 2). After treatment of hydrochlorothiazide, his serum sodium level recovered to between 138 and $142 \mathrm{mEq} / \mathrm{L}$. The patient recovered uneventfully and underwent treatment for Castleman's disease in our hematology department.

\section{Discussion}

Nephrogenic DI is defined as a reduction in urinary concentrating ability, caused by a resistance to the actions of ADH. Patients with an early or mild form of nephrogenic DI show little or no symptoms, as they compensate for their fluid loss with increased water intake. Patients with moderate to severe nephrogenic DI present with polyuria, nocturia, and polydipsia. In severe cases, uncompensated symptoms can develop into marked dehydration, neurologic symptoms, and encephalopathy [2].

Nephrogenic DI can be congenital or may be acquired, as in the present case. Hereditary nephrogenic DI is a common cause of nephrogenic DI in children, while chronic lithium ingestion and hypercalcemia are common causes of nephrogenic DI in adults. Acquired

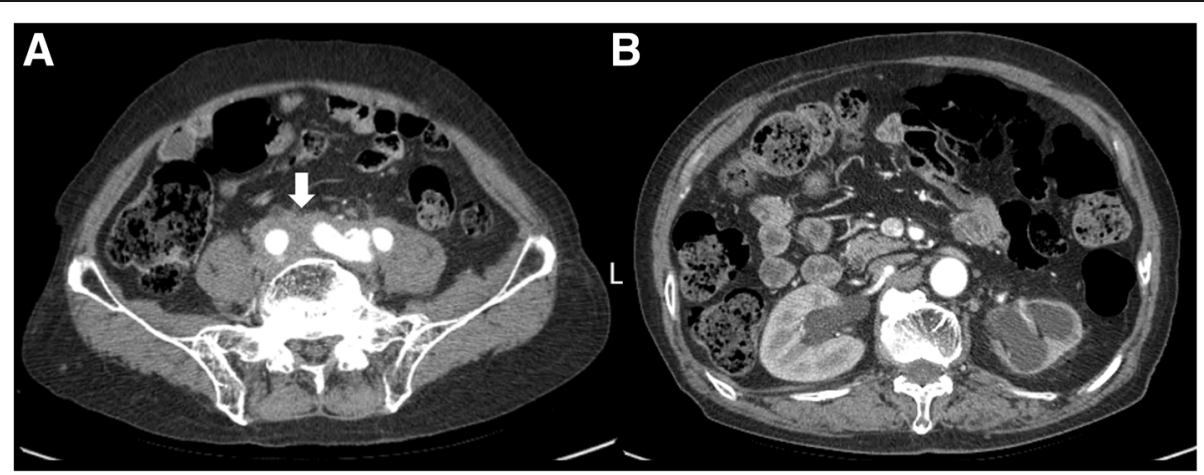

Fig. 1 Abdominal computed tomography $(C T)$. a The retroperitoneal mass surrounding the vessles ranging from the aortic bifurcation to presacral area (arrow). b Both hydronephrosis and atrophied left kidney 


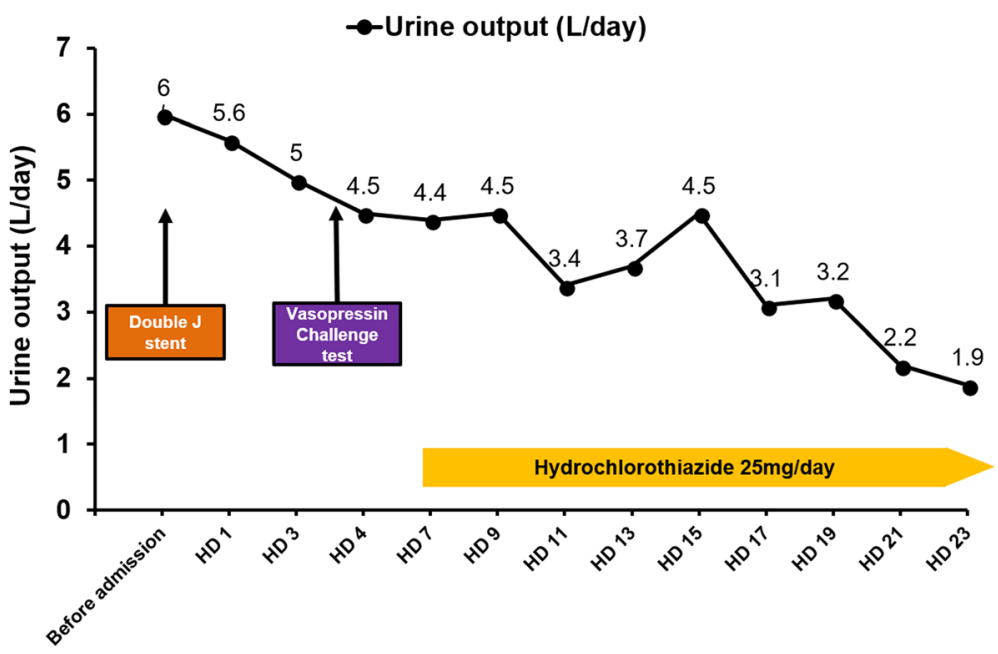

Fig. 2 Change in urine volume during hospitalization. HD, Hospital day

causes are often at least partially reversible, with cessation of the offending drug or correction of the hypercalcemia [8]. Chronic disorders, such as sickle cell disease and kidney failure, can damage the kidney's ability to respond to $\mathrm{ADH}$ [9]. Chronic partial urinary tract obstruction is a rare cause of nephrogenic DI. In two previous reports of such cases, the obstructive uropathy was due to a malignancy (advanced stage ovarian cancer and prostate cancer) $[10,11]$. In these previous cases, the patients' urine output and urine osmolality recovered to normal ranges after surgery and thiazide treatment $[10,11]$. Similarly, the urine output and urine osmolality recovered to normal ranges after treatment in the present case.

The exact cause of the nephrogenic DI in the above-mentioned cases of chronic obstructive uropathy remains unclear, but it is likely that increased pressures on the collecting ducts caused damage to the tubular epithelium, resulting in a resistance to the actions of ADH [10]. In addition, the direct suppression of aquaporin- 2 has been observed in animal models of urinary tract obstruction, which might also explain the mechanism [12].

Castleman's disease comprises a heterogeneous group of lymphoproliferative disorders, with unicentric and multicentric forms. Several cases of Castleman's disease have been reported in patients with retroperitoneal fibrosis. For example, Massaru et al. [13] reported eight cases of Castleman's disease of the retroperitoneum. In 3 of the cases, the retroperitoneum was involved, and in 5 of the cases, the ureter and renal hilum were involved [13]. In addition, there are several case reports of hydronephrosis associated with Castleman's disease involving the ureter [14-16]. However, no cases of partial nephrogenic DI with hydronephrosis caused by Castleman's disease have been previously reported. Thus, the present case is very unique.

\section{Conclusion}

In conclusion, our patient had unicentric Castleman's disease of the hyaline-vascular type, with an initial presentation of bilateral hydronephrosis (identified on CT). Our patient had unique features, presenting with polyuria and polydipsia, and was diagnosed with partial nephrogenic DI. This is the first case of partial nephrogenic DI with hydronephrosis caused by Castleman's disease. Given the rarity of the nephrogenic DI associated with hydronephrosis and Castleman's disease, it is difficult to speculate on the possible associations in a clinical setting. However, if polyuria is present in a patient with Castleman's disease accompanied by retroperitoneal fibrosis, evaluations of obstructive uropathy and nephrogenic DI should be performed.

\section{Additional file}

Additional file 1: Figure S1.Vasopressin challenge test. (TIF $4946 \mathrm{~kb}$ )

Abbreviations

ADH: Antidiuretic hormone; AVP: Arginine vasopressin; CT: Computed tomography; DI: Diabetes insipidus

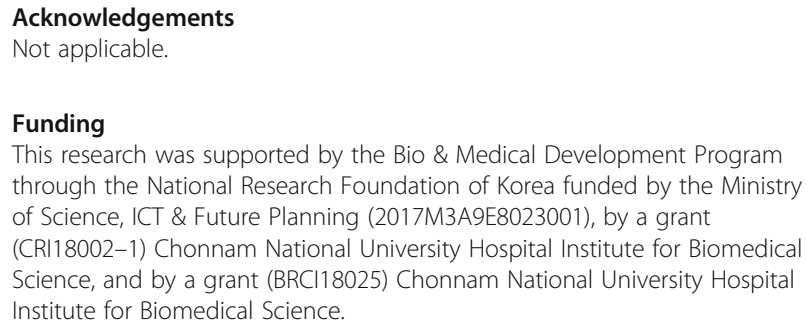

Availability of data and materials

Data regarding the case report belong to clinical and laboratory charts stored in the hospital repository and cannot shared. 


\section{Authors' contributions}

MK contributed in presenting patient's data and writing the manuscript. HSC was involved in clinical care and critically reviewed the manuscript. EHB an SKM performed interpretation of the results. SWK was in charge of the team and revised the manuscript. CSK conceptualized the report, contributed with data collection and interpretation and the manuscript. All authors read and approved the final manuscript.

\section{Ethics approval and consent to participate}

The authors obtained approval from the institutional review board of Chonnam National University Hwasun Hospital (CNUHH-2018-100).

\section{Consent for publication}

Written consent to publish this information was obtained from the patient.

\section{Competing interests}

The authors declare that they have no competing interests.

\section{Publisher's Note}

Springer Nature remains neutral with regard to jurisdictional claims in published maps and institutional affiliations.

Received: 8 September 2018 Accepted: 17 April 2019

Published online: 14 May 2019

\section{References}

1. Robertson GL. Diabetes insipidus: differential diagnosis and management. Best Pract Res Clin Endocrinol Metab. 2016;30(2):205-18.

2. Khanna A. Acquired nephrogenic diabetes insipidus. Semin Nephrol. 2006; 26(3):244-8.

3. Roussak NJ, Oleesky S. Waterlosing nephritis, a syndrome simulating diabetes insipidus. Q J Med. 1954;23(90):147-64.

4. Castleman B, Iverson L, Menendez VP. Localized mediastinal lymphnode hyperplasia resembling thymoma. Cancer. 1956;9(4):822-30

5. Bourque CW. Central mechanisms of osmosensation and systemic osmoregulation. Nat Rev Neurosci. 2008;9(7):519-31.

6. Miller M, Dalakos T, Moses AM, Fellerman H, Streeten DH. Recognition of partial defects in antidiuretic hormone secretion. Ann Intern Med. 1970; 73(5):721-9.

7. Zerbe RL, Robertson GL. A comparison of plasma vasopressin measurements with a standard indirect test in the differential diagnosis of polyuria. N Engl J Med. 1981;305(26):1539-46.

8. Garofeanu CG, Weir M, Rosas-Arellano MP, Henson G, Garg AX, Clark WF. Causes of reversible nephrogenic diabetes insipidus: a systematic review. Am J Kidney Dis. 2005;45(4):626-37.

9. Yoshioka K, Imanishi M, Sakai H, Morikawa T, Okada N, Konishi Y, Tanaka S, Kamikawa S, Kim T, Fujii S. Nephrogenic diabetes insipidus due to hydronephrosis in a patient with a solitary kidney. Clin Exp Nephrol. 2003; 7(3):243-6.

10. Gungor T, Kokanaly MK, Ozturkkan D, Tapisiz OL, Mollamahmutoglu L. A case of nephrogenic diabetes insipidus caused by partial bilateral ureteral obstruction due to advanced stage ovarian carcinoma. Arch Gynecol Obstet. 2009;280(4):679-81.

11. Hong EG, Suh Y, Chung YS, Kim HM, Shin GT, Chung DY, Park RW. A case of nephrogenic diabetes insipidus caused by obstructive uropathy due to prostate cancer. Yonsei Med J. 2000;41(1):150-4.

12. Nielsen S, Kwon TH, Christensen BM, Promeneur D, Frokiaer J, Marples D. Physiology and pathophysiology of renal aquaporins. J Am Soc Nephrol. 1999:10(3):647-63.

13. Kojima M, Nakamura N, Motoori T, Shimizu K, Otuski Y, Haratake J, Ogawa A, Igarashi T, Masawa N, Kobayashi H, et al. Castleman's disease of the retroperitoneum: with special reference to IgG4-related disorder. J Clin Exp Hematop. 2010;50(1):39-44.

14. Hsu HH, Chen YC, Fang JT, Huang CC, Shih LY, Ghuang CK. Unicentric Castleman's disease associated with hydronephrosis. Urology. 2000; 56(5):856.

15. Kim YS, Jung MH. Retroperitoneal Castleman's disease presenting with hydronephrosis indistinguishable from lymphoma. J Obstet Gynaecol Res. 2011;37(8):1145-8.

16. Lee TH, Kim W, Jeong YB, Jang KY, Park SK. Haematuria and hydronephrosis caused by Castleman's disease. NDT plus. 2009;2(6):502-3.

Ready to submit your research? Choose BMC and benefit from:

- fast, convenient online submission

- thorough peer review by experienced researchers in your field

- rapid publication on acceptance

- support for research data, including large and complex data types

- gold Open Access which fosters wider collaboration and increased citations

- maximum visibility for your research: over $100 \mathrm{M}$ website views per year

At $\mathrm{BMC}$, research is always in progress.

Learn more biomedcentral.com/submissions 